\title{
Avaliação de ensino-aprendizagem: um relato de experiência da prova oral na disciplina de Produção Gráfica.
}

\author{
Carolina Calomeno ${ }^{1}$
}

\section{Resumo}

Este artigo relata a experiência da Prova Oral como estratégia de avaliação de ensinoaprendizagem da disciplina de Produção Gráfica, estratégia esta que pode auxiliar para qualificar, analisar e examinar o desenvolvimento tanto do aluno, como do professor. O artigo apresenta um referencial teórico nos eixos temáticos de avaliação e suas estratégias, aprofundado na estratégia de Prova Oral, apresenta brevemente a organização da disciplina, focalizada em explorar práticas mais reflexivas e colaborativas do processo de ensinoaprendizagem, e ainda expõe em detalhes da estratégia da Prova Oral experienciada na disciplina. Ao final, apresentam-se os resultados de uma pesquisa qualitativa a respeito da Prova Oral com os alunos da turma.

Palavras Chave: avaliação de ensino-aprendizagem; prova oral; colaboração.

\section{Introdução}

Na universidade o ensino e a aprendizagem podem ser dois eixos de um mesmo processo, sendo o ensino uma ação sistemática, ordenada e intencional de proposição de conhecimentos e de experiências; e a aprendizagem, o resultado dessa ação, pela aquisição de conhecimentos e pela modificação de comportamentos, ambos experienciados pelo professor e pelo aluno. $\mathrm{O}$ ensinar-aprender assim se estabelece numa relação dialógica entre professor e aluno para a produção de conhecimento e experiência de ambos, ou, segundo Paulo Freire (1996, p.132), para "trazer o outro até a intimidade do movimento de seu pensamento".

Este trabalho é o relato de experiência da prática docente da Prova oral como estratégia para avaliação de ensino-aprendizagem, propondo uma abordagem de avaliação que contemple aspectos individuais, coletivos e colaborativos para a disciplina de Produção Gráfica, do Curso de Design Gráfico da Universidade Federal do Paraná.

\footnotetext{
1 Professora e pesquisadora no Curso de Design Gráfico da Universidade Federal do Paraná. Doutora em Comunicação pela Unisinos (2013), Mestre em Comunicação e Linguagens pela Universidade Tuiuti do Paraná (2005), especialista em Marketing pela UniFAE Centro Universitário (2001), graduada em Design pela UFPR (1992) e técnica em Desenho Industrial pelo CEFET -PR (1987). Atua como pesquisadora nas áreas de Práticas Docentes no Design e Design da Informação. Desenvolve trabalhos relacionados a Cor e Ilustração Botânica. E-mail: carolcalomeno.ufpr@gmail.com.
} 
A avaliação de aprendizagem pode apresentar entendimentos e enfoques diversos, uma vez que não possui um conceito muito fechado. De forma ampla, pode ser conceituada como a “apreciação, o acompanhamento sistemático e a verificação valorativa do processo de ensinoaprendizagem, nas dimensões biopsicossociais do educando" (MARQUES, 1999, p. 152$153)$.

Observa-se que avaliações orais, em especial provas orais, são estratégias pouco utilizadas ao longo das disciplinas nos cursos de graduação em design, embora a habilidade de expressão oral seja importante para um profissional reflexivo e ativo, na apresentação e troca de ideais entre os seus pares. Nos cursos de Design as práticas de avaliação que contemplam estratégias orais, de modo geral, envolvem mais as disciplinas de projeto e o Trabalho de Conclusão de Curso, na defesa oral dos desenvolvimentos e resultados projetuais.

Desse cenário, surgem algumas questões: Como explorar a habilidade oral numa avaliação mais formativa e colaborativa? Como valorizar o repertório do aluno ingressante? E, ainda, como realizar uma avaliação de ensino-aprendizagem que contemple momentos individuais e coletivos?

A partir dessas questões, tenho investigado e aplicado estratégias alternativas de avaliação às tradicionais estratégias de prova escrita para as disciplina que leciono. A experiência aqui relatada, da estratégia de prova oral, tem sido aplicada e refinada ao longo de dois anos, com o auxílio dos alunos e dos colegas professores, os quais vivenciaram a atividade e emitiram suas avaliações em conversas de feedback e por meio de uma pesquisa qualitativa.

\section{Avaliação de aprendizagem e prova oral}

O processo de aprendizagem, segundo Vygotsky (1993), se relaciona com uma alteração cognitiva, ou seja, uma transformação dos saberes do aluno, a qual ocorre por meio das linguagens. Esse pressuposto indica ao professor que utilize múltiplas linguagens, bem como múltiplos procedimentos e estratégias no processo de ensino-aprendizagem, a fim de favorecer o processo cognitivo do aluno (BORBA et. al., 2005, p. 51).

A avaliação está presente em nosso dia-a-dia, em diversos processos sociais e de forma geral nos processos educacionais. Nesses processos educacionais são estabelecidos objetivos, estratégias e atividades, para as quais são atribuídos valores; a partir dos valores, pode-se 
verificar se os objetivos estão sendo alcançados ou não; por conseguinte, as estratégias podem ser alteradas para que os objetivos pretendidos sejam atingidos, compondo um ciclo.

Para a verificação é preciso estabelecer uma estratégia de avaliação. Dentre elas há a testagem, ou seja, a realização de testes ou de provas, as quais se caracterizam por "apresentar uma situação comum a todos que a ela se submetem, tanto em relação às instruções como no que se refere às regras e à valorização de cada questão" (MELCHIOR apud ZANON; ALTHAUS, 2008, p. 3).

A prova oral é uma das estratégias de avaliação que, no âmbito universitário, prevaleceu como instrumento em muitos países europeus desde o século XVIII e continua sendo uma das principais estratégias, como em Oxford e Cambridge (STRAY, 2001). No Brasil, a prova oral tornou-se uma estratégia muito criticada por estar centrada na aferição do professor, portanto com certo grau de subjetividade, vindo a comprometer a credibilidade da mesma e, com isso, sendo desconsiderada como estratégia de avaliação.

Assim como outras estratégias de avaliação, a prova oral apresenta na sua natureza algumas vantagens e desvantagens. Segundo Gil (1994, p.108), as provas orais podem ser abrangentes "para avaliar inúmeros itens, como: profundidade e extensão dos conhecimentos, opiniões, atitudes e habilidade de se expressar oralmente". Podem ainda ser combinadas a outras estratégias que contemplem as demais linguagens - verbal, gráfica, corporal, etc., conforme a natureza do que se quer avaliar.

Em síntese, Gordon Joughin (2010) observa que as avaliações orais são muito interessantes para:

- avaliar a capacidade de resolver problemas aplicados a cenários, os quais podem envolver os alunos uns com os outros e com terceiros (público, cliente, paciente, etc.), ajudando a desenvolver a sua inteligência e autoconsciência;

- sondar parcialmente os conhecimentos dos alunos, de forma a acompanhar o aluno ao longo do processo de ensino-aprendizagem;

- experienciar atividades práticas, com simulações de falar, de ouvir e de responder, nos campos profissionais nos quais a linguagem oral é uma habilidade importante;

- contemplar a capacidade de expressão oral de alguns alunos com necessidades especiais como dislexia, deficiência visual ou outros fatores; 
- esclarecer o significado de questões ambíguas ou pouco claras as quais podem ser novamente expressadas na linguagem do próprio aluno.

Porém a avaliação oral pode apresentar algumas desvantagens, as quais, para Joughin (2010), envolvem:

- trazer ansiedade aos alunos, tanto pelo desconhecimento da dinâmica da estratégia, quanto em se apresentar e/ou em falhar na resposta frente aos colegas;

- realizar uma avaliação extra e/ou especial para alunos com dificuldades auditivas ou de fala;

- dispender um longo tempo de avaliação para classes maiores;

- comprometer a confiabilidade no julgamento da avaliação (pela falta de anonimato, pois o processo ocorre frente a frente) no caso de algum tipo de preconceito expresso pelos avaliadores quanto à etnia, ao gênero e as bases educacionais dos alunos;

- exigir o registro da atividade por meios eletrônicos ou digitais para eventuais recursos.

Para planejar uma avaliação oral, Joughin (2010) ainda sugere observar os seguintes aspectos:

- o que será avaliado (conceitos, teorias, procedimentos, resolução de problemas, competências interpessoais, etc.);

- o nível de interação (de uma pergunta e resposta, de diálogo, de debate com grupo, etc.);

- a autenticidade de simulação, quanto a replicar uma prática oral da "vida real";

- a estrutura da avaliação ou a sequência de eventos, as informações e ferramentas para aplicação (slides explicativos, papel de prova, etc.), seguindo o intuito de reduzir a ansiedade dos alunos;

- quem irá avaliar (professor, professor externo, em pares de alunos, profissional, etc.); 
- a aplicação somente da prova oral ou combinada a outras estratégias (projeto, trabalho escrito, representação gráfica, etc.);

- a validade da avaliação: a) quanto à elaboração de perguntas e questões suficientemente abrangentes aos temas da disciplina; b) quanto ao efeito que a avaliação proporciona na aprendizagem dos alunos; c) quanto à repercussão dos resultados no processo de ensino;

- a confiabilidade quanto à replicação da avaliação com critérios e padrões estruturados (variando o cenário, os professores, as turmas).

Para a disciplina de Produção Gráfica, o planejamento da prova oral contemplou, além das indicações de Joughin (2010), a postura do professor como agente reflexivo, valorizando a avaliação como verificação, e não puramente como um instrumento de valoração. Ainda foram enfatizados na avaliação os componentes: (1) de cooperação, almejando descentralizar a aferição dos resultados, do professor para os alunos, e propondo uma atmosfera mais colaborativa para a avaliação da expressão do conhecimento; e (2) do entendimento e das articulações dos alunos quanto às experiências vividas na disciplina.

\section{A disciplina de Produção Gráfica}

Produção Gráfica é uma disciplina optativa do Curso de Design Gráfico, associada ao Departamento de Design da UFPR, e vem sendo ofertada desde 2014, com a carga horária de 30 horas semestrais e duas horas/aula por semana (DEDESIGN, 2016), na qual alunos de qualquer período ou outros cursos podem se matricular.

Pela natureza de disciplina optativa, apresenta algumas peculiaridades, sendo uma das mais impactantes sua ementa de conteúdo programático aberto, o que permite a livre exploração de temáticas relevantes e pertinentes ao Curso de Design Gráfico. Sendo assim, a disciplina pode ser moldada para as necessidades específicas do grupo de alunos, a cada ano.

Pela nomenclatura da disciplina, a expectativa dos alunos quanto aos conteúdos programáticos circulam entre: a) processos de impressão artesanais, tradicionais e especiais; b) processos de acabamentos gráficos e encadernação; c) encaminhamento de material para a produção; e d) orçamento e relacionamento com fornecedores.

Entretanto, os conteúdos e demais componentes do plano da disciplina (objetivos, avaliações/valores, cronograma, etc.) têm sido discutidos e definidos, como já mencionado, 
entre professor e alunos. Dessa forma, a definição do plano da disciplina ocorre em conjunto, de modo a atender a grande diversidade repertorial dos alunos, os quais se encontram em períodos (e, por vezes, em cursos) diferentes.

Em geral, nos últimos anos a disciplina tem se configurado como uma disciplina de caráter técnico-projetual, pois confere ao designer subsídios para projetar e produzir com êxito o seu projeto. Por conta disso, cabe destacar outra peculiaridade da disciplina: a diversidade de termos, processos e materiais para produção gráfica. Os alunos precisam desse conhecimento para explorar as características materiais e expressividades gráficas em seus projetos, bem como para constituir um vocabulário que lhes permita estabelecer um diálogo com as instâncias produtoras.

A avaliação da Prova Oral é aplicada ao final da disciplina de Produção Gráfica, com vistas a realizar uma revisão, uma verificação final de todo o processo ali vivenciado.

Conforme apresenta a Figura 1, o ciclo da disciplina se desenvolve continuamente e a preparação da Prova Oral começa a ser composta no primeiro dia de aula, com o levantamento de temas de interesse e geração de questões por parte dos alunos. Os temas são abordados ao longo do semestre e constituem o foco das demais avaliações. A aplicação da Prova Oral ocorre no penúltimo dia de aula, simultaneamente à verificação/análise dos resultados que, por sua vez, estende-se à última aula por meio de uma conversa ampla com os alunos a respeito do transcorrer da disciplina. 


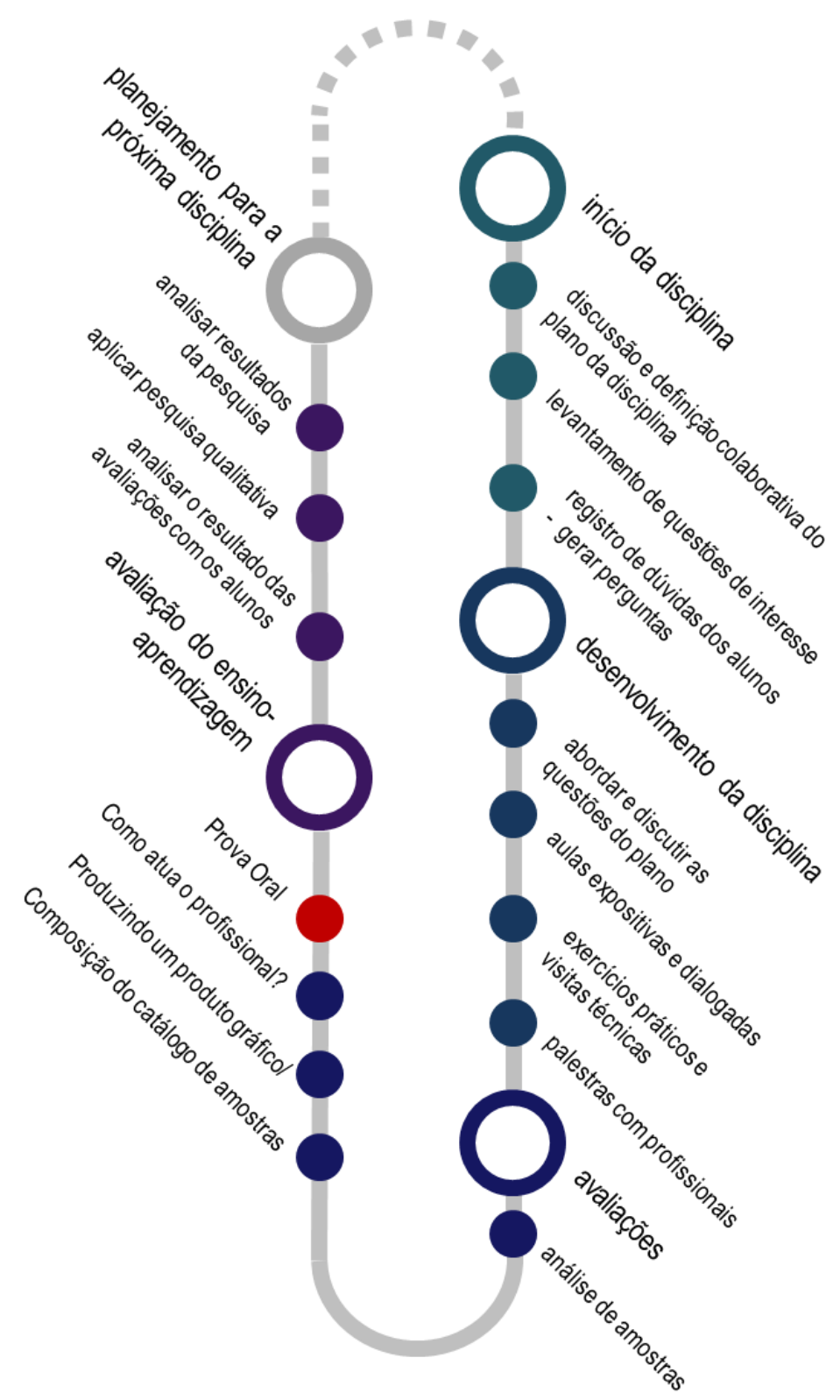

Figura 1: Diagrama da disciplina de Produção Gráfica (autor, 2016).

\section{A estratégia da Prova Oral}

A prova oral é abordada na disciplina como uma estratégia de verificação de ensinoaprendizagem que revisita os temas e questões iniciais da disciplina; que constata a apropriação de termos, processos, materiais e suas expressividades para produção gráfica; e que ainda explora as linguagens verbais orais (resposta oral), verbais escritas (preparação da resposta) e gráficas (diagrama da resposta).

Participam da aplicação da Prova Oral o professor da disciplina, um professor convidado ou monitor da pós-graduação e a turma de alunos. 
No início da aula, primeiramente, a dinâmica da avaliação é apresentada aos alunos, que são informados a respeito da gravação da prova e sobre a possibilidade de acesso à gravação, para futuras consultas. Em seguida as questões são sorteadas aos alunos (uma questão para cada aluno), que recebem uma folha para o registro da sua questão, bem como para elaborarem a resposta (na forma de texto, palavras-chave, diagramas ou desenhos).

O tempo total previsto para a atividade é de 100 minutos (aproximadamente), sendo:

- 5 minutos para explicação da dinâmica e distribuição das folhas de prova;

- 5 minutos para sorteio de perguntas, impressas em tiras de papel;

- 15 minutos para os alunos prepararem a resposta, com o registro na folha de prova;

- 75 minutos de arguição, sendo cada aluno arguido individualmente e a sua resposta conferida pela turma.

A mediação é realizada pelos professores; caso a resposta seja considerada incompleta, pode ser complementada por outro aluno. No caso de uma resposta equivocada ou se o aluno não soube responder, outro aluno poderá responder aquela questão.

Cada aluno pode responder e/ou completar no máximo quatro respostas do colega, somando assim pontos extras. Caso o aluno não tenha respondido nenhuma questão, nem angariado pontuação no processo de avaliação, o aluno pode responder extraclasse, por escrito, e apresentar na aula seguinte.

O roteiro das perguntas do professor está organizado de acordo com os eixos temáticos da disciplina e com isso há um encadeamento das respostas. O professor auxiliar se responsabiliza pelo registro de pontos dos alunos.

\section{Os resultados}

Na aplicação da Prova Oral o que se observa, conforme relatam os alunos, é uma apreensão inicial pelo desconhecimento da estratégia, mas ao longo da atividade o clima da turma se torna mais descontraído e se instaura um ambiente de colaboração, no auxílio à resposta dos colegas. Observa-se também um alto nível de concentração, pois as questões são arguidas aleatoriamente e uma resposta pode colaborar com a outra. Na verificação especificamente da estratégia em si, em pesquisa qualitativa (via formulário do Google Drive) junto aos alunos, 
do total de 30 (trinta) alunos, 20 (vinte) alunos relataram opiniões positivas, 6 (seis) opiniões positivas com sugestões e 4 (quatro) alunos relataram descontentamento quanto ao tipo de avaliação.

Sob o ponto de vista da aprendizagem, do meio ao final do tempo da prova os alunos passam a reconhecer as suas questões, propostas no ingresso na disciplina, e o quanto angariaram repertório e experiências a respeito dos temas de Produção Gráfica. Na medida em que verificam isso, eles mesmos assimilam o que antes era dúvida, percebendo assim a transformação cognitiva efetuada (Vygotsky, 1993).

Já sob o ponto de vista do ensino, observa-se que essa estratégia de avaliação permite trabalhar muitas questões (mais de 40), com diversidade de temas e complexidades; permite ainda aferir e retificar (pelos pares e pelo professor) informações no mesmo momento da resposta. Percebe-se que os alunos tem um insight quanto à revisão do que aprenderam, e o professor também pode verificar quais são os temas e/ou conteúdos mais complexos, os mais difíceis de serem aprendidos ou que deveriam ser tratados com outras abordagens.

\section{Considerações Finais}

A estratégia de avaliação da Prova Oral aqui relatada é uma das estratégias adotadas para a verificação de ensino-aprendizagem. Considero-a promissora por explorar as habilidades orais individuais, o aspecto coletivo com a colaboração da turma na atividade e ainda o aspecto formativo, com o reconhecimento pelo aluno do seu processo de desenvolvimento cognitivo quanto à Produção Gráfica. Anualmente essa estratégia tem sido aprimorada, considerando para a próxima disciplina a formatação de uma estratégia híbrida (verbal escrita/oral) e também a ampliação do caráter colaborativo da atividade, envolvendo mais ativamente o grupo de alunos para aprenderem entre si.

\section{Learning-teaching assessment: an experience report of the oral test in the discipline of Graphic Design Production.}

\section{Abstract}

This article reports the oral examination experience as a strategy to evaluate the teaching and learning in the discipline of graphic design production. This methodology can provide 
support to qualify, to analyze and to examine the development of both, the learning of the students and the teacher. The article presents a theoretical scheme about assessments in student groups and strategies for oral assessments. It presents briefly the organization of the discipline, focusing to explore more reflective and collaborative practices in the teachinglearning process. Further a strategy diagram is presented of the oral assessment experience in that discipline. Finally the results of a qualitative research in oral assessment tests with students in class is exposed.

Keywords: learning-teaching assessment; oral examination; collaboration.

\section{Referências}

BORBA, A. M.; FERRI, C.; HOSTINS, R. C. L. Avaliação da aprendizagem no ensino superior: questões que emergem da prática docente. Contrapontos (UNIVALI), v. 7, p. 43-54, 2007.

FREIRE, P. Pedagogia da Autonomia. São Paulo: Paz e Terra. 1996.

DEDESIGN - Site. Disponível em: <http://www.sacod.ufpr.br/portal/dedesign/>. Acesso em: 10 set. 2016.

GIL, A. C. Metodologia do ensino superior. 2. ed. São Paulo: Atlas, 1994.

MARQUES, H. R. Metodologia do ensino superior. Campo Grande : UCDB, 1999.

STRAY, C. The shift from oral to written examination: Cambridge and Oxford 1700-1900.

Assessment in Education: Principles, Policy and Practices, v. 8, n. 1, 2001.

JOUGHIN, G. A Short Guide to Oral Assessment. Leeds: Leeds Metropolitan University/The University of Wollongong, 2010. Disponível em: <

http://www.leedsbeckett.ac.uk/publications/files/100317_36668_ShortGuideOralAssess1_WEB .pdf>. Acesso em:10 set. 2016.

VYGOTSKY, L S. Pensamento e linguagem. São Paulo: Martins Fontes, 1993.

ZANON, D. P.; ALTHAUS, M. M. Instrumentos de avaliação na prática pedagógica

universitária. Publicação independente (texto apresentado na Semana Pedagógica promovida pela PROGRAD da UEPG em fevereiro de 2008). Ponta Grossa, 2008. Disponível em: < http://ltc-ead.nutes.ufrj.br/constructore/objetos/InstrumentosdeAvaliacao.pdf >. Acesso em: 10 set. 2016. 